\title{
KANT ON THE OBJECT-DEPENDENCE OF INTUITION AND HALLUCINATION
}

\author{
Forthcoming in The Philosophical Quarterly \\ Andrew Stephenson \\ Trinity College, University of Oxford
}

\section{Keywords}

Kant, Object-Dependence, Intuition, Hallucination, Naïve Realism

\begin{abstract}
Against a view currently popular in the literature it is argued that Kant was not a naïve realist about perceptual experience. Naive realism entails that perceptual experience is object-dependent in a very strong sense. In the first half of the paper I explain what this claim amounts to and I undermine the evidence that has been marshalled in support of attributing it to Kant. In the second half of the paper I develop in some detail an account of Kant's theory of hallucination and explain why no such account is available to someone who thinks that veridical perceptual experience is object-dependent in the naïve realist sense. Kant's theory provides for a remarkably sophisticated, bottom-up explanation of the phenomenal character of hallucinatory episodes, and although it has been little studied, it is crucial for gaining a proper understanding of his model of the mind and its place in nature.
\end{abstract}




\section{Introduction}

What is intuition? This is one of the central questions of Kant scholarship. It is also one of the most divisive. Recently the key point of contention has been whether or not intuition essentially involves the understanding and its conceptual capacities. At the forefront of those who argue that it does not are Robert Hanna and Lucy Allais. ${ }^{1}$ However, both Hanna and Allais make a further, distinct claim about intuition, one that in recent years has become a standard view yet which has so far received much less critical scrutiny. ${ }^{2}$ Hanna and Allais not only take intuition to be in some strong sense independent from the understanding. They also take it to be in some strong sense dependent on the object. I will refine what this means in what follows, but in a nutshell the claim is that an intuition depends for its very existence on the current, real existence of its object, for it just is the presentation to consciousness of a real object that is currently present. Both Hanna and Allais draw on contemporary work in philosophy of perception and the thought is that Kant's account of intuition displays significant affinities to a relational or naïve realist account of perceptual experience.

In this paper I argue against this reading of intuition while remaining neutral on the conceptualism/non-conceptualism debate. In $\$ \$ I-3$ I outline three progressively weaker forms of the claim that intuition is object-dependent and argue that the weakest form of the claim is just as well supported by those texts which Hanna and Allais (among others) take to support the strongest form of the claim. In $\$_{4}$ I present further textual evidence to support my case. Here I draw primarily on Kant's Anthropology from a pragmatic point of view, a later work that has been rather neglected in the literature on the theoretical philosophy. I show that Kant certainly did not reserve the term 'intuition' ('Anschauung') for a state that is object-dependent in the very strong sense that is often assumed. Unfortunately, this fact does not quite settle matters. It remains open to my opponents to claim that Kant was terminologically inconsistent: that the primary use of 'intuition' remains to denote a state that is object-dependent in the strongest sense, though admittedly the term is sometimes used to refer to a

\footnotetext{
${ }^{1}$ See especially Hanna (2005, 2008) and Allais (2009).

2 Though see Roche (2OII). Roche's primary focus is Allais' interpretation of transcendental idealism, which will not be my concern here.
} 
different kind of state altogether. To counter this move, I consider Kant's account of hallucination in $\$ 5$ and in $\$ 6$ argue that such an account is incompatible with the attribution of any strong form of object-dependence to even the veridical cases of intuition. A relationalist or naïve realist just cannot give the kind of account of hallucination that Kant gives. Therefore the readings of Hanna and Allais (among others) would have Kant not only terminologically but also philosophically inconsistent. As with the Anthropology itself, Kant's views on hallucination have been somewhat neglected in the literature. ${ }^{3}$ Yet we shall see that they are crucial for gaining a proper understanding of Kant's model of the mind and its place in nature.

Before I begin, two caveats regarding scope. First, I conduct the discussion within a framework of empirical realism and will not be concerned with the interpretation of transcendental idealism. Kant repeatedly affirms his commitment to empirical realism. For example: 'empirical realism is beyond doubt, i.e. to our outer intuitions there corresponds something real in space' $\left(\mathrm{A}_{375}\right){ }^{4}$ And many other things Kant says confirm this commitment. Of particular relevance here is his insistence on there being a distinction within the realm of appearance between the object as it is in-itself and the object as it merely appears, between reality and ideality, objective and subjective validity, truth and illusion, being and seeming, and so forth. ${ }^{5}$ I will not try to define precisely what Kant's empirical realism amounts to. To do so would require engaging at length with transcendental idealism. But Kant clearly has a rich conception of how we human animals cognitively interact with the spatiotemporal objects around us, and this conception can be fruitfully explored on its own terms. After all, in the course of vehemently defending his realist credentials against the spurious criticisms of the Feder-Garve Review at the end

\footnotetext{
${ }^{3}$ One well-known exception is Beck (1978). Beck does not in fact spend much time addressing positively Kant's account of hallucination. Rather he focuses on the absolutely correct and consummately summarised the point that 'the categories do not differentiate veridical from nonveridical experience; they make the difference between dumbly facing chaos without even knowing it - "less even than a dream" - and telling a connected story, even if it is false' (54).

${ }^{4}$ See Bxxxix-xli, A28/B44, A35/B52, B69, B274-9, A367-80; Prolegomena (4: 292-4, 374-5). With the exception of the Critique of Pure Reason, which is cited using the traditional A/B format, all references to Kant's works are given by the volume and page number in the German Academy edition and are accompanied by a short English title. The details of the English translations that I have consulted are given in the list of references at the end.

${ }^{5}$ See, e.g., A45-6/B62-3, B69-7I, Ar83/B227, A293-8/B349-54; Prolegomena (4: 289, 290-I, 375).
} 
of the Prolegomena, Kant observes of the 'sort of idealism it is that runs through my entire work' that it 'does not by far constitute the soul of the system' (4: 374).

Second, I focus primarily on outer empirical intuition. I do not discuss pure intuition and I will only briefly discuss matters relating to inner intuition ( $\$ 2$ and $\$ 5$ ). Accordingly, by 'objects' I mean external empirical objects: physical entities that exist in space and time (whatever exactly this amounts to for Kant). Examples include trees, houses, and ships. Moreover, I will only be concerned with outer empirical intuition as it functions in perceptual experience. One might think it is also involved in certain kinds of non-perceptual episode, such as singular thought. ${ }^{6} \mathrm{I}$ do not discuss this issue here.

\section{Strong-Particular-Dependence}

Here are Hanna and Allais on intuition:

an intuition is essentially relational and existential. It is relational in the sense that its structure is dyadic - it always contains places for both the intuiting subject and the intuited object. And it is existential in the sense that the place for the intuited object is always filled (Hanna 20or: 2IO)

intuition is essentially a relational form of cognition, in that the existence of the object of intuition is a necessary condition of both the objective validity or cognitive significance of the intuition and also the existence of the intuition itself: if the putative object of an intuition fails to exist, then it is not only not an objectively valid intuition, it is not even authentically an intuition (Hanna 2005: 259)

intuitions represent objects immediately because they present the particular object itself, as opposed to being representations that enable us to think about it whether it is present or not (Allais 2009: 389)

intuitions represent objects immediately because they present the object itself, as opposed to referring to an object through the mediation of further representations (which enable us to think about the object whether it is present or not). Immediacy says that an intuition is not

${ }^{6}$ See, e.g., Howell (I973). 
simply a representation which is caused by a particular thing, but that it is in fact a presentation to consciousness of that thing. (Allais 2010: 59)

My view is that Kant's concern is not just with causal origin (provided by sensation) but with the actual presence of the object: the contrast is between a representationalist version of externalism, which says that what mental states represent is essentially linked to their causes, and a relational view, which sees perceptual states as involving their objects as constituents (Allais 20I0: 60)

Hanna emphasises existence while Allais emphasises presence, but it is clear that they both attribute to intuition a very strong form of object-dependence, which I will call Strong-Particular-Dependence.

Strong-Particular-Dependence: If, at time $t$, a subject $s$ intuits an object $o$, then: at $t, o$ exists and is present to $s$.

I specified 'object' and 'exists' above - we are talking about outer empirical objects and their empirically real existence in space and time. By 'subject' is meant a human subject: a discursive, partially passive intellect possessive of two fundamental cognitive faculties, sensibility and understanding. To be present to a subject is to be located (and not occluded from view) in that subject's physical perception-space, her field of vision, for example.

Strong-Particular-Dependence articulates a necessary condition on intuition. The claim is that without the current existence and presence of some particular physical object, there can be no intuition.

Drawing on contemporary work in philosophy of perception, both Hanna and Allais connect this strong form of object-dependence to a relational view of perceptual experience. Let the phenomenal character of a perceptual experience consist of its phenomenal properties, roughly those properties of an experience which determine what it is like for a subject to undergo it. Then the relevant relational view says that (at least some of) these phenomenal properties are relations to real physical objects. Recall that for present purposes we are treating intuition as the Kantian analogue of what we today call perceptual experience, so granted three very plausible assumptions, this view entails Strong-ParticularDependence. The assumptions are: (a) all perceptual experience has a phenomenal character, (b) relations require the existence of their relata, and (c) the perceptual nature of the relations with which we are concerned require not 
only that their object-relata exist but also that these object-relata be located (and not occluded from view) in the subject's perception-space.

Such relational views of perceptual experience are sometimes called naïve realist theories. Perceptual experience seems to put us in touch with the world directly: it seems to present us with the objects themselves (as well as with their properties), rather than with private mental entities that are merely caused by objects or with existentially quantified propositions that merely descriptively specify objects. The view can be called naïve, then, because unlike sense-data theories (a very different kind of relationalism) or certain forms of representationalism, it says that things really are as they seem. Perceptual experience really does put us in touch with the world directly; it really does present us with the objects themselves. This has important consequences for the treatment of non-veridical experience - for cases in which things are precisely not as they seem - and I will return to this issue in $\$ \$ 5-6$. For now, I just want to point out that the commitment to Strong-Particular-Dependence is in fact not unique to the relational/naïve realist view that Hanna and Allais draw on in their interpretations of Kant.

In the last of the above passages, Allais contrasts her relational version of externalism, 'which sees perceptual states as involving their objects as constituents' with 'a representationalist version of externalism, which says that what mental states represent is essentially linked to their causes'. But this is a little misleading. Representationalist versions of externalism can also, like Allais' view, be construed as taking perceptual states to involve their objects as constituents. One might, for instance, view perceptual experience as a representational mental state with propositional content, but then analyse propositions as structures that literally contain objects. ${ }^{7}$ In the terms that Allais uses in the other passages quoted above, such representationalist versions of externalism no more allow us to undergo perceptual experience of objects in their absence than does her own relational version of externalism. The point is not that there are no differences between these views. There certainly are. The

\footnotetext{
7 See Speaks (2009). This view of content is sometimes called 'Russellian', following the account of propositions found in Russell (1903), but this term is also used to refer to quite different accounts of content - e.g. in Chalmers (2004). For an alternative representationalist view that is also object-involving in the required sense, see McDowell (1996) and Brewer (1999).
} 
point is that representationalists can still be committed to Strong-ParticularDependence so long as they construe representational content in a certain way. Here, then, is Marcus Willaschek, whose account Allais has in mind as contrasting with her own:

To be sure, one can believe that one has a 'house-intuition'. But if there is no house there, it only seems to one as if one had an intuition of a house. In reality there is only the intuition of something else (as in the case of illusion), or there is not an intuition at all, but rather a hallucination, which one mistakenly takes for an intuition. (Willaschek 1997: 547, my translation)

Allais' putative contrast notwithstanding, Willaschek is clearly committed to Strong-Particular-Dependence. He thinks that without the current existence and presence of an object, there can be no genuine intuition of that object. At best there can be something that the subject erroneously takes for an intuition of that object. But either this is in fact an intuition of some other object, one that does exist and is present, or else it is not in fact a genuine intuition at all but rather a mere hallucination.

In arguing that it is a mistake to attribute Strong-Particular-Dependence to intuition, and correspondingly that it is a mistake to contrast intuition and hallucination since the latter is a species of the former, I will focus on the interpretations of Hanna and Allais. They are the most recent and most developed versions of my target view. But the view is widespread, and my arguments will tell against any version of it. ${ }^{8}$

\section{Weak-Particular-Dependence}

What textual evidence is there in support of attributing Strong-ParticularDependence to intuition? Both Hanna and Allais appeal to the following passage

\footnotetext{
${ }^{8}$ See, e.g., McLear (forthcoming), Gomes (20I4), Tolley (20I3: II6), McLear (2OII: I3), Buroker (2006: 37), Setiya (2004: 66), Warren (I998: 22I), and Cassam (I993: II7). See Grüne (2009: 42$3)$, on the other hand, for a recent example of someone who explicitly rejects the StrongParticular-Dependence reading.
} 
from Kant's Prolegomena, though in doing so neither quotes the second sentence: ${ }^{9}$

Intuition is a representation as would depend immediately on the presence of the object. It therefore seems impossible originally to intuit a priori, since then the intuition would have to occur without an object being present, either previously or now, to which it could refer, and so it could not be intuition. (4: 28I-2, last italics mine)

The first thing that might give us pause here is the subjunctive tone. Does Kant mean to suggest that while one might think that intuition depends immediately on the presence of an object, in fact it does not? Reflection on the wider context of the passage suggests otherwise. Kant's question in this part of the Prolegomena is how pure mathematics is possible. His answer is that pure mathematics is possible through pure intuition. Kant is simply using the subjunctive to draw attention to an apparent tension between the possibility of pure intuition and the dependence of intuition on the presence of an object. This is an issue for Kant precisely because he wants to maintain both. Pure intuition is possible - it must be because it is necessary for the possibility of pure mathematics and pure mathematics is possible. And dependence on the presence of an object constitutes a genuine condition on intuition.

But still the question remains what exactly this condition amounts to. Kant's talk in the second sentence of the presence of the object 'either previously or now' ('weder vorher, noch jetzt') suggests that it cannot quite be Strong-ParticularDependence. Strong-Particular-Dependence demands that the presence of the object be concurrent with the intuition of it: if, at time $t$, a subject $s$ intuits an object $o$, then at $t, o$ exists and is present to $s$. Dropping this concurrency demand yields what I will call Weak-Particular-Dependence:

Weak-Particular-Dependence: If, at time $t$, a subject $s$ intuits an object $o$, then: at $t$ or some time $t_{<t}$ previous to $t, o$ exists and is present to $s$.

Versions of externalism much weaker than those mentioned in \$I would entail Weak-Particular-Dependence. One need no longer construe intuition as relational or as having object-involving representational content. The condition

${ }^{9}$ Allais (2010: 62, 64) does quote the second sentence but in a different context and she doesn't discuss how it seems to tell against her take on the first sentence. 
does remain broadly externalist, however. According to Weak-ParticularDependence, what one can intuit is still determined by facts external to the subject. Indeed, while the object of intuition need no longer exist and be present at the time of the intuition, just it must at some previous time have existed and been present. That is, the particular object of intuition retains its place on the right-hand side of the conditional.

This weaker kind of externalist picture - unlike Willaschek's - certainly warrants being contrasted with Allais' on the central matter of object-dependence. But given Kant's talk of an object being present either previously or now, it is at most the weaker picture that is supported by the above passage from the Prolegomena. In fact I will argue that Weak-Particular-Dependence is still too strong a condition on intuition - it is indicative of a shift towards a more general causal requirement but it does not go far enough in this direction. First, however, there is one other passage that has been used as direct textual support for the attribution to intuition of Strong-Particular-Dependence.

Hanna (200I: 209-IO, 2005: 259) cites a passage from towards the end of the Transcendental Aesthetic. Again it is worth paying attention to context. Here is the sentence in full:

If one will not make them [i.e. space and time] into objective forms of all things, then no alternative remains but to make them into subjective forms of our mode of outer as well as inner intuition, which is called sensible because it is not original, i.e., one through which the existence of the object of intuition is itself given (and that, so far as we can have insight, can only pertain to the original being); rather it is dependent on the existence of the object, thus it is possible only insofar as the representational capacity of the subject is affected through that. (B72)

This case is not quite as straightforward as the previous one. Kant does not in this passage explicitly suggest that intuition can be of objects that were only previously present. Nevertheless, consideration of the wider point that Kant is making here shows us that it does not support the attribution to intuition of Strong-Particular-Dependence.

Kant's concern is to contrast the original or divine mode of intuition with the derivative, human mode of intuition. The first thing to note is that, if we attribute Strong-Particular-Dependence to human intuition, then this contrast 
cannot be understood as follows: the existence of an intuition in the divine case entails the existence of its object, whereas the existence of an intuition in the human case does not entail the existence of its object. According to StrongParticular-Dependence, the human mode of intuition just as much as the divine is such that the existence of an intuition entails the existence of the object of intuition. If we were to attribute Strong-Particular-Dependence to human intuition, this mere existence-entailment cannot be what Kant means when he characterises divine intuition as 'one through which the existence of the object of intuition is itself given'. The Strong-Particular-Dependence reading would need something stronger.

Perhaps, then, Kant has the following contrast is mind: divine intuition is a mode of intuition such that the intuition is itself the ground of the existence of the intuited object, whereas this relationship is reversed for the human mode of intuition. Human intuition is such that the intuited object is itself the ground of the existence of the intuition. So far, so good - those who want to attribute Strong-Particular-Dependence to human intuition can make sense of the distinction Kant wants to draw here. However, suppose we now ask how, for humans, does the object ground the existence of the intuition? Kant's answer in the above passage is that the object grounds the existence of the intuition 'insofar as the representational capacity of the subject is affected'. But now it looks like Kant's contrast is merely that between a mode of intuition which depends on affection by the object - human intuition - and a mode of intuition that does not depend on affection by the object - divine intuition. And we do not need to attribute Strong-Particular-Dependence to human intuition in order to capture this contrast. Weak-Particular-Dependence would capture it just as well. As would an even weaker condition that I will introduce in the next section.

Making sense of Kant's contrast between divine and human intuition does not require attributing Strong-Particular-Dependence to human intuition. (Indeed, doing so even makes the distinction less clear, for it implies that there are significant similarities between the two modes of intuition.) Therefore the above passage does not support the attribution to human intuition of StrongParticular-Dependence.

Before moving on, I want briefly to say something about a group of texts that one might think supports the Strong-Particular-Dependence reading in a more 
indirect way, namely the Refutation of Idealism (B274-9) and its associated redrafts (Notes I8: 306-I2, 6IO-23). ${ }^{10}$ I cannot hope to give a full account of these complex and controversial texts here, but nor, I think, do I need to. In these texts Kant argues in various ways for various forms of the thesis that 'the mere, but empirically determined, consciousness of my own existence proves the existence of objects in space outside me' (B275). He is careful, however, to make clear that to secure this central thesis it had to be proven only that inner experience in general is possible only through outer experience in general (B278-9, my italics). This general dependence claim can hold even if one can occur without the other in particular cases. Specifically, Kant frequently points out that his position leaves ample room for the possibility of at least occasional hallucination, so long, that is, as it remains parasitic in a suitable way on the normal channels of passive sensing through genuine affection by external objects (see especially B278-9, and Notes I8: 307, 310, 62I). I will explore how this works in \$5. For now it suffices to say two things.

First regarding the general dependence claim. It is a matter of some dispute whether or not Kant's notion of experience should be construed factively. This gives rise to two readings of the general dependence claim. On the factive construal of experience, the claim is simply a clarification or reformulation of the central thesis. On the non-factive construal of experience, the claim is weaker than, and on its own does not entail, the central thesis. I have argued elsewhere that, at least in certain key contexts, experience should be construed nonfactively (Stephenson 20II). But I need not rely on this here. For on neither construal of experience does the Refutation support the Strong-ParticularDependence reading.

If we construe experience non-factively, then the point I need to make is that the general dependence claim would entail the central thesis if conjoined with either Weak-Particular-Dependence or the still weaker form of object-dependence I outline in the next section. To be sure, Strong-Particular-Dependence would also be sufficient for the argument, but it is in no way necessary. (Of course this is to say nothing as to the soundness of the argument. The point is only that, precisely

\footnotetext{
${ }^{10}$ See also the A-edition fourth Paralogism (A366-80), which the Refutation effectively replaced.
} 
as Kant says, everything depends on whether a case can be made for the general dependence claim.)

If, on the other hand, we construe experience factively, then the point becomes a broader one. At least on the face of it, the refutation of external world scepticism is not what is at stake between those versions of representationalism in which representational content is not understood as object-involving and, say, naïve realism. For even if the naïve realist is right about the nature of perceptual experience, the question remains as to whether we in fact enjoy perceptual experience so conceived. Now perhaps it could be shown that there is nevertheless some non-obvious route to the refutation of scepticism that is only available to the naïve realist. ${ }^{11}$ But even then it would be another thing altogether to tie this route to Kant's own. This brings me to my second point.

Some commentators, albeit not strictly confining themselves to the Refutation and its redrafts, have found in Kant material suggestive of an argument for the stronger, particular form of the dependence claim, namely that every single occasion of the empirically determined consciousness of my own existence depends on the simultaneous existence of some external object. ${ }^{12}$ Even this does not support the Strong-Particular-Dependence reading of intuition.

The claim here, more specifically, is that Kant might have endorsed some version of the embodied mind thesis. As Hanna (2006: 73) puts it: 'necessarily for every creature cognitively constituted like me, a self-conscious awareness of its own uniquely determined stream of consciousness in inner sense requires the existence of its own body in space'. Although this claim might indeed provide a response to the sceptic as Kant conceives her in the Refutation, it does not entail Strong-Particular-Dependence. For even supposing we supplement the embodied mind thesis with the further claim that the subject's own really existing and present body must be one of the objects in every act of her intuitional awareness, it is obviously not the case that it must be the sole object of every such act. External objects other than one's own body can be intuited distal things like trees, houses, and ships can be the value of $o$ in the formula.

${ }^{11}$ See Logue (20II) for an overview. She concludes that naïve realism offers no special anti-sceptical advantages.

${ }^{12}$ See Cassam (1993), Hanna (2006), and Rukgaber (2009). 
Strong-Particular-Dependence says of these things too that they must exist and be present if they are to be intuited. There is no such commitment in the claim that the human mind is essentially embodied - the view is entirely compatible with non-naïve realist (etc.) theories of perceptual experience.

\section{General-Affection-Dependence}

I will now outline a third and final kind of object-dependence, which I will call General-Affection-Dependence. We have already seen Kant talk about affection in the same sentence as talking about object-dependence, and although GeneralAffection-Dependence will bear little resemblance to object-dependence as understood in contemporary philosophy, I will argue in the rest of this paper that all things considered it is the best candidate for what Kant himself means by the phrase.

The basic idea behind General-Affection-Dependence is Kant's core doctrine that while both sensibility and the understanding have a priori forms, all the matter for cognition must be given. ${ }^{13}$ For as Kant says in the B-edition Introduction to first Critique:

how else should the cognitive faculty be awakened into exercise if not through objects that stimulate our senses and in part themselves produce representations, in part bring the activity of our understanding into motion to compare these, to connect or separate them, and thus to work up the raw material of sensible impressions into a cognition of objects (BI)

And again in the opening paragraph of the B-edition Transcendental Aesthetic:

In whatever way and through whatever means a cognition may relate to objects, that through which it refers immediately to them, and at which all thought as a means is directed as an end, is intuition. This, however, takes place only insofar as the object is given to us; but this in turn, at least for us humans, is possible only if it affects the mind in a certain way. (B33)

\footnotetext{
${ }^{13}$ See A20/B34, A86/Bir8. As the Anthropology has it: 'without sensibility there would be no material that could be processed' (7: I44).
} 
In keeping with our framework of empirical realism, I will take Kant's talk of the stimulation of our senses and objects affecting our mind to mean causal affection by physical objects. General-Affection-Dependence can thus be characterised as follows:

General-Affection-Dependence: If, at time $t$, a subject $s$ intuits an object $o$ utilising matter $m$, then: at $t$ or $t_{<t}, m$ has been given to $s$ through causal affection.

The new terminology involved in this characterisation of General-AffectionDependence requires some explanation. The matter that comprises an intuition consists of a manifold of sensations. Sensations are 'the effect of an object on the capacity for representation' (Ar9/B34). They are the immediate result of subjects being causally affected by objects. As such, they provide what Kant calls the 'raw material' of cognition (AI, BI), and thus of intuition, a species of cognition $\left(\mathrm{A}_{320} / \mathrm{B}_{376}\right)$. We can best understand this role, I suggest, by employing a dataprocessor model. Sensations provide the raw material of intuition by encoding information about the objects that cause them through affecting us.

The notion of information-encoding may at first sound rather anachronistic, but it is simply supposed to latch on to the idea that sensations have different properties in virtue of the different circumstances in which they are brought about, and that it is these properties that are exploited in various ways by those processes or faculties for which they provide the raw material. Sensations count as encoding information, then, simply by having the properties they do.

This requires that there must be some regular correspondence between the properties of the sensations and the properties of the objects about which the sensations encode information. But we needn't say anything more specific than this. For property $F$ of sensation $a$ to be that in virtue of possessing which $a$ counts as encoding information about object $o$, say specifically about property $G$ of $o$, it must be the case that $G$-like properties of $o$-like objects regularly correspond to $F$-like properties of $a$-like sensations. ${ }^{14}$

\footnotetext{
${ }^{14}$ Kant very often talks about sensations corresponding to objects. See A20/B34, Aı66, B207, Ai43/Bi82, A58I/B609, A723/B75I, and less explicitly Ai68/B209 and Ai7o/B2II-I2.
} 
Sensations act as cognitive proxies for objects, representing objects, we might say, by standing in for them. ${ }^{15}$ Note that this is not at all to say that sensations themselves are the normal objects of awareness for Kant. It is to say that the 'subjective' sense in which they represent objects is quite different to the 'objective' sense in which cognitions do so. And note also that regular correspondence does not entail resemblance. $F$ and $G$ themselves need not be in any way qualitatively similar to one another. Thus we can maintain that the notion of information-encoding is a suitable one with which to characterise Kant's conception of sensation while at the same time acknowledging what he says in the Prolegomena (4: 290): 'I can attach no sense... to the assertion that the sensation of red is similar to the property of cinnabar that excites this sensation in me.' The naturalism embedded in talk of information-encoding does nothing to debar Kant's anti-Humeanism on this point.

Significantly, this understanding of sensations does not in itself entail that General-Affection-Dependence places any externalist constraints on intuition whatsoever. Sensations are internal states of the subject that have informationencoding properties in virtue of having other properties. Now these informationencoding properties are certainly externalist properties: whether or not they are possessed depends essentially on factors external to the subject. This is a consequence of the regular-correspondence requirement. But unless one maintains further that these information-encoding properties are essential to the identity of the sensations themselves, to their individuation, it does not follow that sensations themselves depend essentially on factors external to the subject. I currently possess the externalist property of being seated at my computer, but this is not one of my essential properties: I could get up and walk around and I would still be me. Perhaps the information-encoding properties of sensations are like this. For it might well be the case that sensations can be individuated solely on the basis of the other properties they possess - those that ground their information-encoding properties. And whether or not these properties are possessed might not depend at all on external factors.

Suppose again that sensation $a$ possesses property $F$, and in virtue of a regular correspondence between $F$ and property $G$ of object $o, a$ thereby also possesses

${ }^{15}$ This 'standing-in-for' locution is from Rosenberg (1980), who takes his lead from Sellars (1968). See also Landy (2008: 242) and Chapter 3 of Rosenberg (2005). 
property $I$, that of encoding information about $o$. $I$ depends essentially on external facts about $o$. But if possessing $F$ is sufficient to individuate $a$ and $F$ does not itself depend on external facts about $o$, which for all I have said here it need not, then it follows that $a$ can be individuated without regard to external facts about $o$.

For all I have said here, then, General-Affection-Dependence is compatible with an entirely internalist reading of intuition. This is not to say that what I have said is incompatible with an externalist reading of Kant. For one thing, these labels can denote a wide variety of views. But it is worth noting that if there is a single distinctive feature of the externalist project, it lies in putting our knowledge of the external world on a par with our knowledge of the internal world. ${ }^{16}$ This is worth noting because such parity can be achieved in either of two ways. One can begin by granting that our knowledge of the internal world is direct and then go on to argue that our knowledge of the external world is also direct, which is the route taken by the version of externalism attributed to Kant by Hanna and Allais (et al.). But one might pursue an equally externalist project by first granting that our knowledge of the external world is indirect and then arguing that our knowledge of the internal world is also indirect. There is strong evidence that Kant conceived of his project as externalist in the umbrella sense, but which particular form this externalism took is far less clear. ${ }^{17}$

General-Affection-Dependence articulates a necessary condition on intuition: if there is to be an intuition of an object, then the sensational matter of that intuition must have been acquired in virtue of the subject being causally affected by objects. This defines a very weak notion of object-dependence indeed. Unlike Strong-Particular-Dependence it does not require that the object of intuition

\footnotetext{
${ }^{16}$ See Chapter I of Stalnaker (2008).

${ }^{17}$ Again I have in mind here the Refutation of Idealism and associated texts (cited at the end of \$2). Kant certainly argues that there is a special kind of parallelism between internal and external cognition. But he generally focuses on the fact of parallelism itself - that internal and external cognition are on a par. When it comes to specifying whether this fact obtains because external cognition is promoted to the traditional status of internal cognition or rather because internal cognition is demoted to the traditional status of external cognition, he seems far more ambivalent in various places he both affirms and denies that external cognition is immediate and he both affirms and denies that internal cognition is immediate. Also pertinent to the present point are the A- and B-edition Transcendental Deductions (A84-I30/BII6-69). For some relevant discussion see Stephenson (2014).
} 
exist or be present at the time of the intuition. And unlike both StrongParticular-Dependence and Weak-Particular-Dependence, it makes no mention at all on the right-hand side of the conditional of the particular object of intuition. It therefore does not require that the particular object of intuition ever existed or was present. The claim is simply that the partial passivity of the human mind engenders a very general dependence on causal affection by objects insofar as it is to have any matter for use in intuition. Exactly when or how such matter is used is not specified.

Nevertheless, in picking out this dependence on causal affection, GeneralAffection-Dependence does account for Kant's contrast between human and divine intuition at least as well as do Strong- and Weak-Particular-Dependence, and so is at least as well supported by the passage from the Transcendental Aesthetic quoted in $\$_{2}$. Unlike divine intuition, human intuition 'is possible only insofar as the representational capacity of the subject is affected' (B72).

Likewise for the passage from the Prolegomena also quoted in \$2. There Kant's worry was that pure intuition seems impossible because it would mean that 'the intuition would have to occur without an object being present, either previously or now' (4: 282). General-Affection-Dependence still generates this worry. And as an additional point, the implication here is that empirical intuition is dependent on an object being present either previously or now, but note Kant's use of the indefinite article ('die Anschauung alsdenn ohne einen weder vorher, noch jetzt gegenwärtig Gegenstand', my italics). One way to read this is as suggesting that empirical intuition merely depends on the sometime presence of some object or other. Not only need the particular object of intuition not be present at the time of the intuition - the particular object of an intuition need never have been present. General-Affection-Dependence is the only form of the object-dependence condition weak enough to allow for this.

So far I have undermined the textual evidence that has been marshalled in support of attributing Strong-Particular-Dependence to intuition, in the process introducing two significantly weaker forms of object-dependence, the stillexternalist Weak-Particular-Dependence and the externalist-neutral GeneralAffection-Dependence. I have also mounted an initial case in favour of GeneralAffection-Dependence: it is based on the core Kantian doctrine that all matter for cognition must be given through affection and it makes good sense of the 
texts we have seen. In the next section I present further evidence to support my case against Strong-Particular-Dependence. Then, in the following section, I sketch an account of Kant's model of hallucination on the basis of these new texts. This account is incompatible with both Strong- and Weak-ParticularDependence, and, in the final section, it will also provide the platform for a more systematic argument against Strong-Particular-Dependence and for General-Affection-Dependence.

\section{Imagination}

Here are two passages from Kant's Anthropology from a pragmatic point of view:

Sensibility in the cognitive faculty (the faculty of representations in the intuition) contains two parts: sense and the power of imagination. - The first is the faculty of intuition in the presence of the object, the second the faculty of intuition even without the presence of the object. (7: 153)

The power of imagination (facultas imaginandi), as a faculty of intuition even without the presence of the object, is either productive, that is, a faculty of the original presentation of the object (exhibitio originaria), which thus precedes experience; or reproductive, a faculty of the derivative presentation of the object (exhibitio derivativa), which brings back into the mind an empirical intuition had previously. (7: 167)

It is clear that in these passages Kant is not thinking of intuition as a kind of state that depends for its existence on the real, current presence of its object. Sensibility remains the faculty of intuition, but it is now divided into two parts, sense and imagination. The latter is the faculty of intuition even without the presence of the object.

One initial response on behalf of those who want to attribute Strong-ParticularDependence to intuition might be that these passages, first published in 1798 , represent a change of view to that found in the Critique of Pure Reason (178I/7). But this is not very plausible. We find similar passages transcribed in several of the student notes to Kant's lectures on metaphysics, including those dated between the A- and B-editions of the Critique. Here is a passage from the Mrongovius notes of $1782-3$ : 
Time and space are conditions of sensible representations, all of which rest on the faculty of intuition. The faculty of intuition, insofar as it begins from the presence of the object, is sense; insofar as it is without object, but yet is in respect to space and time, is power of imagination... (29: 88I)

From the Volckmann notes of I784-5:

We perceive in ourselves a specific feature of the understanding and reason, namely consciousness, if I take this away there still remains something left yet, namely, sensation, imagination, the former is intuition with presence, the latter without presence of the object... (28: 449)

And finally, from the Dohna notes of I792-3:

Power of imagination is the substitution of the senses, the faculty of intuitions in the absence of objects. (28: 673)

It is unsurprising that Kant is working with a conception of the imagination as the ability to represent absent objects. This view was quite standard at the time and is found in Baumgarten's Metaphysics, the textbook Kant took for his lectures. What is notable is rather that Kant seems to have no qualms in nonetheless classifying the imagination as a faculty of intuition, or with talking about intuitions in the absence of objects.

Allais (2010: 59, 2011: 395) has put some weight on the fact that, in a remark on the Refutation of Idealism, Kant admits only that it does not follow that every intuitive representation [anschauliche Vorstellung] of outer things includes at the same time their existence, for that may well be the mere effect of the imagination (in dreams as well as in delusions)' (B278). Here Kant does not attribute intuitions per se to the imagination, but rather merely intuitive representations. Allais fails to note, however, that Kant is not so cautious in the corresponding footnote in the B-edition Preface, where he straightforwardly says that which intuitions belong to sense and which to imagination still needs to be decided in each particular case (Bxli); nor indeed is he so cautious elsewhere in the Refutation itself - in a footnote on immediacy he equates 'imagining something as external' with 'exhibiting it to sense in intuition' (B276). And so in light of the 
passages I have just cited - and there are many more like them, both in Kant's own hand and from student notes to his lectures on logic and anthropology ${ }^{18}-\mathrm{I}$ cannot agree that the rare turn of phrase found at one point in the Refutation is especially significant.

Finally, it is worth noting that Kant's definition of the imagination even in the B-edition Transcendental Deduction itself - a definitive source if ever there was one - is at best ambiguous. There he says 'Einbildungskraft ist das Vermögen, einen Gegenstand auch ohne dessen Gegenwart in der Anschauung vorzustellen' (BISI). Guyer and Wood translate this as: 'Imagination is the faculty for representing an object even without its presence in intuition'. That is, in choosing to preserve as far as possible the original word order, they have 'in intuition' as a constituent of the adverbial phrase 'even without its presence in intuition'. But in the original German it is just as natural, if not more so, to read 'in intuition' as being outside of the scope of the phrase 'even without its presence', that is, as directly modifying 'representing' rather than 'its presence'. One way to capture this point in English would be with the following translation: 'Imagination is the faculty for representing an object in intuition even without its presence'. In which case this central text says that the imagination's representing of an object is done in intuition and yet in the absence of the represented object.

There is, then, no reason to doubt that the passages from the Anthropology represent Kant consistent and considered view on the structure and role of sensibility as the faculty of intuition. Imagination, at least in one of its guises, is a subfaculty within sensibility, one that enables the intuition of objects even without their presence or existence. Strong-Particular-Dependence is not a necessary condition on intuition.

So far, however, one might worry that this is a merely verbal dispute. One might, for instance, argue that the English verb 'to see' has both a factive and a nonfactive sense. But doing so would tell us little concerning the metaphysical issue of whether both senses denote fundamentally the same kind of state, or whether it is rather the case that the factive sense denotes a kind of state that is object-

18 See Metaphysics $L_{I}$ (28: 230), dated mid-I770s; Notes (I5: 86), dated 1783-4; Mrongovius Anthropology (25: I30I), dated I784-5; Metaphysics $L_{2}$ (28: 585), dated I790-I; Notes (I8: 6I8-I9), dated I790-I; Dohna-Wundlacken Logic (24: 70I, 705, 753), dated I792. 
dependent in the sense of Strong-Particular-Dependence while the non-factive sense denotes an altogether different kind of state. Similarly, it remains open to my opponents to admit that Kant often calls the products of the imagination intuitions and nonetheless to insist that Strong-Particular-Dependence picks out something crucial about those intuitions that are not the product of the imagination. ${ }^{19}$ That is, perhaps those versions of externalism that entail StrongParticular-Dependence - relationalism or naïve realism and certain objectinvolving forms of representationalism - provide useful models on which to understand Kant's theory of 'intuition-with-the-presencelexistence-of-the-object'.

This would by no means be an easy position to defend. Allais (2009: 389, 2010: 59) proposes that her reading of intuition offers the most straightforward reading of the immediacy and singularity criteria. But this too is no longer plausible. Kant uses these criteria even in those texts where he talks about intuition without the presence/existence of objects, so admitting equivocation in the term 'intuition' would also require admitting equivocation in the terms 'immediate' and 'singular'. More straightforward would therefore be to take these criteria to mean that intuitions present their objects in a peculiarly phenomenological way the particular objects we perceptually experience at least seem to be really there. This would still provide us with the necessary contrast to purely conceptual thought. When I abstractly judge that some trees are green, for example, no particular tree even seems to be really there. And it would also allow us to apply the criteria univocally to intuition in general, both with and without the real presence/existence of the object.

But in fact things are even worse than this for those who would attribute StrongParticular-Dependence to intuition. The problem with such views is not merely

${ }^{19}$ Colin McLear (20I4) has recently proposed just such a view. He suggests that Kant himself, and with familiar terminology, marks a distinction between intuitions that have StrongParticular-Dependence as a condition and those that require merely mental images: the former are outer intuitions, the latter inner intuitions. I am not convinced by the textual support McLear gives for this reading (Notes I8: 6I9-2I). After all, Kant does not mark the distinction in this way in any of the texts we have seen. Nevertheless, this interesting proposal deserves more discussion than I can give it here. For one thing, it would embroil us in issues concerning what it is for space and time to be the pure forms of intuition. I will just point out that, as a version of the Strong-Particular-Dependence reading, it remains susceptible to the argument I go on to articulate in the final sections of this paper. 
that they lack simplicity as well as solid textual motivation. They also render Kant's account inconsistent in a more substantive way.

\section{Hallucination}

Let us look more closely at the reproductive imagination, that part of sensibility 'which brings back into the mind an empirical intuition had previously'. Normally, this subfaculty would function in cognitive processes that are entirely epistemically legitimate, like memory (Anthropology 7: 182-5), or indeed in everyday veridical perceptual experience (Aıоo-2) - commentators often connect it to processes of perceptual binding and working memory. ${ }^{20}$ But there is space here for an altogether more pernicious function for the reproductive imagination - in hallucination. Consider the following simple model:

Hallucination Model I: If a subject $s$ undergoes at time $t$ an intuition $i$ of some object $o$ and $i$ is veridical, then $o$ is causally affecting $s$ at $t$ in such a way that $s$ qualifies as sensing $o$ at $t$, and it is in virtue of this occurrent act of sensing that $s$ undergoes sensations that encode information about $o$, which information is utilized at $t$ to produce $i$. If, however, $i$ is hallucinatory, then $o$ is not causally affecting $s$ at $t$ in such a way that $s$ qualifies as sensing $o$ at $t$, for $o$ is not present at $t$ at all. Instead there is at $t$ in $s$ the imaginative retrieval of information about $o$ that was originally acquired through $s$ sensing $o$ at some time $t_{<t}$ previous to $t$, which information is utilized at $t$ to produce $i$.

The first thing to note is that, according to Hallucination Model $\mathrm{I}$, the information provided by the reproductive imagination for producing hallucinatory intuition must at some point prior to the hallucination have been acquired through the normal passive channels - the causal affection of the senses by physical objects. Thus in the Anthropology Kant goes on to point out the ultimately derivative or parasitic nature of the imagination in this very naturalistic guise:

\footnotetext{
${ }^{20}$ See Kitcher (1990: 84-6), Brook (1997: 34-6, I24), Van Cleve (I999: 243-4), and Westphal (2004: 89).
} 
imagination is nevertheless not exactly creative, for it is not capable of producing a sense representation that was never given to our faculty of sense; one can always furnish evidence of the material of its representations. To one who has never seen red among the seven colours, we can never make this sensation comprehensible... the sensations produced by the five senses in their composition cannot be made by means of the power of imagination, but must be drawn originally from the faculty of sense. $(7: 167-8)^{21}$

However, this is not to say that, for Kant, it is impossible for a subject to hallucinate something she has never actually encountered - a unicorn, say, or a pink elephant. But now the imagination even in its naturalistic, reproductive manifestation must do something a little more than regurgitate information in exactly the form it was given. Recall that our data-processor model allows us to make quite fine-grained distinctions among the content of sensibility, distinguishing not just intuitions themselves but also the information-encoding sensations out of which intuitions are built. In these terms, we need to attribute to the reproductive imagination powers of manifold-rearrangement, so that it can reorganise previously given information to produce sensible manifolds that are (relatively) novel. All the information being worked on in such a process must, at some point previously, have been acquired through genuine causal affection by physical objects - in the unicorn case, horses and horns; in the pink elephant case, pink things and elephants. But once this has occurred, the reproductive imagination can gerrymander its own manifolds to be utilised as the matter in intuitions of unencountered objects. As Kant puts it in a note dated 1785-9: 'without an outer sense, whose representations we merely repeat and combine in a different way... we would not be able to have any dreams at all' (Notes I8: 310, italics mine). Call this Hallucination Model II.

Hallucination Model II: If, utilising matter $m$, a subject $s$ undergoes at time $t$ an hallucinatory intuition $i$ of some object $o$, then $o$ is not causally affecting $s$ at $t$ in such a way that $s$ qualifies as sensing $o$ at $t$, for $o$ is not present at $t$ at all. Instead there is at $t$ in $s$ the imaginative retrieval of $m$, all the informational content of which was acquired at some previous time $t_{<t}$ in virtue of $s$ being causally affected by objects suitably similar to $o$ in their observational properties.

${ }^{21}$ Cf. A770-I/B798-9; Vienna Logic (24: 904); Notes (18: 309-10, 613, 619). 
Note that this does not require attributing to the reproductive imagination powers of conceptual recognition - Hallucination Model II remains neutral on the conceptualism/non-conceptualism debate. For recall that sensations encode information simply by having their properties. Thus all the reproductive imagination need be able to do in order to gerrymander novel manifolds is discriminate between sensations on the basis of their properties. And this is by no means a conceptual capacity. It involves no understanding of what the information encoded in the sensations means. The conceptualism/nonconceptualism debate revolves around the question of whether specifically conceptual processes are involved in the production of intuition. All parties can agree that non-conceptual processes - perceptual binding and so forth - are involved. The current model merely extends the scope of such processes.

Hallucination Model I was only incompatible with the attribution of StrongParticular-Dependence to intuition generally. Hallucination Model II, assuming that some objects other than $o$ are suitably similar to $o$ in their observational properties, is also incompatible with the attribution of Weak-ParticularDependence to intuition generally - according to Hallucination Model II, there is a species of intuition that does not depend on the particular objects of intuition ever having existed or ever having been present. All of this favours the case for General-Affection-Dependence as the correct reading of Kant's talk of object-dependence as a general condition on intuition. By now I have done a lot to undermine the textual case for Strong-Particular-Dependence, and, given the structure and function of sensibility in constituting intuitions out of sensations, Weak-Particular-Dependence seems a somewhat unstable compromise. Still, we do not yet have an argument against attributing Strong-Particular-Dependence to those intuitions that occur in the presence of their objects; that is, we do not yet have an argument against the claim that, despite Kant's inclusive talk, his theory is best seen as one on which veridical and hallucinatory intuition are fundamentally different kinds of state. For this we need to introduce one more complication into Kant's account of hallucination.

First a quick cautionary note. In what follows I will occasionally talk as though sensibility itself produces intuition. Now, one way of putting the conceptualist claim is to deny this and to insist rather that the understanding produces intuition, the role of sensibility being merely to provide the matter for intuition. But another way to state essentially the same position would be to allow that 
sensibility itself produces intuition while insisting that it can do so only because the understanding is itself active in sensibility. In talking as though sensibility produces intuition, I do not mean to presuppose that the conceptualist reading is wrong. I simply assume the second formulation of the conceptualist reading, and I do this simply because it allows me to formulate certain points more clearly. Everything I say here remains neutral on the conceptualism/non-conceptualism issue.

One crucial feature of hallucination is the fact that it seems entirely possible that things might go perceptually awry without the subject noticing or even being able to notice. We need not go as far as entertaining radical sceptical hypotheses. Even working within the framework of Kant's empirical realism we must concede that there might be nothing intrinsic to the data we process that tells us whether it is the result of current affection or rather of some more surreptitious procedure. Indeed, we might even concede that there is always something intrinsic to the data that could tell us this much, at least when we take a large enough collection of it. It would still seem entirely possible that this feature is not always accessible to us, and this is enough to motivate the worry. It is a worry of which Kant is clearly well aware. In the Anthropology:

the power of imagination, which puts material under the understanding in order to provide content for its concepts (for cognition), seems to provide a reality to its (invented) intuitions because of the analogy between them and real perceptions. (7: 169)

And in the Prolegomena:

The difference between truth and dream, however, is not decided through the quality of the representations that are referred to objects, for they are the same in both $(4: 290)$

At the level at which sensible information is processed for use in judgement, there might, at least under certain circumstances, be no way to tell the proximal origin of the representations that encode that information. The understanding, as the seat of self-consciousness, cannot reach down into sensibility in order to check whether or not the reproductive imagination was active in a problematic way. This is part of what makes error possible - when, as Kant puts it in the Critique, 'the faculty of judgement is misled through the influence of the imagination' (A295/B352). In contemporary terms, Kant allows that veridical 
intuition and hallucinatory intuition can be introspectively indiscriminable. ${ }^{22}$ And in fact, Kant's model of the mind is not just one on which this problem arises. Crucially, it also has the resources to explain a little further why this problem arises.

One might assume that sense and the reproductive imagination operate quite independently of one another in their production of intuition. The data regurgitated by the reproductive imagination must originally be given through the entirely passive, receptive operation of sense, but once this has occurred, the faculty bypasses sense altogether at the time at which it actually produces hallucinatory intuition. However, I have already mentioned that the reproductive imagination has a role even in veridical intuition - in the acts of working memory and perceptual binding that help to, as it were, hold the intuition together through time. And what I want to suggest is that the converse is also the case, that sense plays a direct role even in hallucinatory intuition.

Kant divides sense into two principle parts, outer sense and inner sense. In the Anthropology he characterises this distinction as follows: 'The first [i.e. outer sense] is where the human body is affected by physical things; the second [i.e. inner sense] where it is affected by the mind' (7: 153). ${ }^{23}$ Suppose that some entirely passive, receptive part of sensibility is always involved in the production of intuitions, whether they be veridical or hallucinatory. What distinguishes hallucinatory intuition from veridical intuition at this level of mental function is not the bypassing of the senses altogether. What distinguishes hallucinatory intuition from veridical intuition at this level of mental function is whether or not outer sense specifically is activated at the time of the intuition. In hallucinatory intuition, it is not. In hallucinatory intuition, it is the reproductive imagination rather than the object that fulfils the role of proximal causal instigator. Yet it does so not by itself producing intuition directly from its

\footnotetext{
${ }^{22}$ Kant himself comes very close to expressing the issue with this terminology in Notes (I8: 62I).

${ }^{23}$ Again it would not be very plausible to claim that this passage represents a late development in Kant's view. We find very similar passages in notes to the metaphysics lectures running right from the mid-I770s to the early I790s: Mrongovius Metaphysics (29: 882), Metaphysics $L_{I}$ (28: 224-5, 23I), Metaphysics $L_{2}$ (28: 585), Dohna Metaphysics (28: 673), and Metaphysics $K_{2}(28: 738)$.
} 
regurgitated information. The imagination's regurgitated information is first processed through inner sense. In the Critique Kant focuses on distinguishing this faculty from apperception and relating this distinction to the epistemic humility of transcendental idealism (Bi52-6). But in the Anthropology he talks instead about:

taking the appearances of inner sense for external appearances, that is, taking imaginings for sensations... it is mental illness: the tendency to accept the play of representations of inner sense as experiential cognition, although it is only fiction... and accordingly to trick oneself with the intuitions thus formed (dreaming when awake). (7: I6I)

The addition of this intermediary step re-emphasises the important point that the kind of imaginational 'activity' currently under discussion is very different from the conceptual activity of the understanding. The reproductive imagination fully replaces the object and is attributed similar causal powers. After all, surely hallucinatory intuition involves actually undergoing sensuous modifications of the mind as opposed to a mere punctiform episode of information recall. Call this Hallucination Model III.

Hallucination Model III: If, utilising matter $m$, a subject $s$ undergoes at time $t$ an hallucinatory intuition $i$ of some object $o$, then $o$ is not causally affecting $s$ at $t$ in such a way that $s$ qualifies as sensing $o$ at $t$, for $o$ is not present at $t$ at all. Instead there is at $t$ in $s$ the imaginative reproduction of $m$, all the informational content of which was acquired through outer sense at some previous time $t_{<t}$ in virtue of $s$ being causally affected by objects suitably similar to $o$ in their observational properties. $m$ is then presented to inner sense and processed in the normal way to produce intuition.

Hallucination Model III places the reproductive imagination between outer and inner sense. And the crucial point is that exactly this structure is operative in veridical intuition: information originally received through outer sense is filtered first through the reproductive imagination and then through inner sense. Sensibility, for Kant, does not consist of two entirely separate subfaculties, each operating in isolation to produce their own variety of intuition. Rather it consists of a single complex but integrated faculty.

This picture has several appealing features. One is its promise to yield an attractively straightforward understanding of certain aspects of Kant's otherwise 
rather intractable doctrine of inner sense, specifically the claims that all intuitive representations whatsoever belong to inner sense (A34/B50, A98-9), that inner sense nonetheless has no manifold of its own (B67), and that inner sense involves self-affection (B67-8, Bi53-6).

And it is also fair to say, I think, that the naturalistic account of the reproductive imagination embodied in Hallucination Model III brings us closer to the prephilosophical idea of imagination many of us would have prior to reading the Deduction and Schematism chapters. The primary role of the imagination in those chapters is neither reproductive nor naturalistic. But despite its relative neglect in the literature, this should in no way suggest that the imagination in its current guise is insignificant. For one thing, it provides a mechanism that contributes towards quite a rich, bottom-up explanation of hallucination. In particular, what we have here is an explanation of the phenomenal character of hallucination, of why things seem the way they do to a subject undergoing hallucination, which is to say, potentially indistinguishable from the way in which things seem to a subject undergoing veridical intuition. It is this feature of the current model that I want to exploit in the last section of this paper.

\section{Explanation}

Let us return to those forms of externalism that entail Strong-ParticularDependence: relationalism or naïve realism, the view that intuition essentially involves relations to real physical objects; and versions of representationalism on which intuition essentially involves object-involving propositional content. 'Essentially' is important here. According to these views, Strong-ParticularDependence is a necessary feature of intuition. That the object of intuition exists and is present at the time of the intuition is part of what makes intuition the kind of state it is. We saw in $\$_{4}$ that this is not plausible as an account of intuition in general, but the worry was that it might nevertheless be true of veridical intuition.

However, such strongly externalist readings of veridical intuition would not in fact be neutral on the nature of hallucinatory intuition. They are committed to saying that veridical intuition and hallucinatory intuition are fundamentally different kinds of state. (That is, they are both forms of disjunctivism about 
perceptual experience, the view that veridical and hallucinatory cases are not of fundamentally the same kind, and that therefore any characterisation able to capture the nature of both kinds would have to take a disjunctive form.) For hallucinatory intuition is certainly not a kind of state that requires the presence and existence of its object. The point of the last section, then, was to show that Kant's model of hallucinatory intuition is not of this ilk.

For Kant, I have argued, there are fundamental similarities between veridical and hallucinatory intuition. Both involve the presentation of sensational information that has been processed through inner sense in exactly the same way. And both also depend on the prior manipulation of this information by the reproductive imagination. In hallucinatory intuition this involves the reproduction of information-encoding manifolds of sensation not currently being provided through outer sense, but even in veridical experience it involves the preconceptual, associative organisation of such manifolds.

Allais (2009: 394) is of course right when she says that 'The relational view of perception is not undermined by the existence of cognitive processing'. But the bare existence of cognitive processing in veridical intuition is not the problem here. The problem is that the cognitive processing in veridical intuition is, on Kant's, (a) shared by hallucinatory intuition and (b) sufficient to explain the phenomenal character of hallucinatory intuition, specifically of how it can be introspectively indiscriminable from veridical intuition.

Suppose that I am veridically intuiting a tree. In doing so I might attend to various of the tree's features, the shape and colour of its leaves, its height, the length of its branches and so forth. Now suppose that, instead of attending to the tree itself, I introspectively attend to my intuition of the tree. What might this involve? Perhaps it would involve becoming more aware of the limitations of my eyesight and thus of my discriminatory abilities, or it might involve attending to what it feels like when my pupils contract or dilate in response to changes in brightness. But surely it would still involve attending to the tree - the tree does not disappear from view when I start to introspect. And since attending to my intuition of a tree involves attending to the tree, the tree itself seems to me to be literally a constituent of my intuition. Recall that relationalism is sometimes called naïve realism because it says that the explanation of the fact that veridical intuitions seem to have physical objects as literal constituents is that 
they do have physical objects as literal constituents. But then of course hallucinatory intuition too can seem this way - it can be introspectively indiscriminable from veridical intuition. So the worry is that if we allow that seeming this way in the hallucinatory case can be explained both without appeal to the existence or presence of the intuited object and by cognitive processes that are common across all cases, hallucinatory or veridical, then there is nothing to stop the same explanation also serving in the veridical case. The kind of rich, bottom-up explanation of hallucination that Kant provides would undercut the claim that the current presence of really existing objects plays any essential role in accounting for how things seem when one undergoes a veridical intuition. ${ }^{24}$

For this reason contemporary relationalists/naïve realists are restricted to an extremely austere characterisation of hallucination purely in terms of the negative epistemic property of being introspectively indiscriminable from veridical perception. Here is M. G. F. Martin (2006: 369):

For certain visual experiences as of a white picket fence, namely causally matching hallucinations, there is no more to the phenomenal character of such experiences than that of being indiscriminable from corresponding visual perceptions of a white picket fence as what it is.

And Matthew Nudds (2009: 344) on the same issue:

The NR [naïve realist] must deny that there is anything in common to all experiences that purport to present the same thing that could explain their doing so: all that can be said about hallucinatory experiences that purportedly present objects is that they are introspectively indiscriminable from experiences that actually present objects.

It remains a matter of dispute whether such an account of hallucination could suffice. ${ }^{25}$ But the point here is simply that the account is clearly very alien to Kant's own. Introspective indiscriminability is not a primitive for Kant. It is a consequence of the fact that inner sense is active in hallucinatory intuition in exactly the way it is active in veridical intuition. Whatever matter the

\footnotetext{
${ }^{24}$ This kind of 'screening off' argument is due to Martin (2004: 6I-3). See also Martin (2006: 368 70).

${ }^{25}$ See Siegel (2008) and Sturgeon (2008) for criticisms of Martin to which Nudds replies.
} 
understanding has to work with in its acts of judgement and self-awareness, it is presented to the understanding through inner sense.

The situation would be almost exactly parallel for any representationalist version of the Strong-Particular-Dependence reading. These views are motivated more by semantic issues than phenomenological ones, and accordingly would not so closely concern phenomenal character or introspective indiscriminability. The claim would rather be that the current presence of really existing objects plays an essential role in explaining the representational content of veridical intuition. But then the relevant commitment simply becomes that hallucinatory intuition has an altogether different kind of representational content. And so now the problem is that, given the close structural similarity between Kant's account of veridical and hallucinatory intuition, we have as yet seen no reason whatsoever to think that he takes them to have fundamentally different kinds of content.

Allais (20II: 380) has said that 'whether and how illusion and hallucination pose problems for a direct theory of perception... is simply not one of Kant's concerns'. This strikes me as a rather radical claim. Not only were precisely such concerns a major feature of the Platonic and Augustinian rationalism out of which grew the Early Modern tradition in which Kant received his philosophical education. More specifically, they also played an extremely prominent role in Descartes' notorious method of doubt, which led directly to the kind of recalcitrant sceptical worries Kant so famously considered 'a scandal of philosophy' (Bxxxix). And they were no less prominent in the distinctively empiricist thought of David Hume, the remembrance of whom so famously interrupted Kant in his dogmatic slumber (Prolegomena 4: 260). I have argued that Allais' claim is false.

Note, however, that this should not suggest that I have here taken any stance on whether or not Kant was particularly concerned with scepticism. Scepticism, it seems to me, is not the issue; or at least, it needn't be. For although considerations about non-veridical perception might be developed in the direction of arguments for scepticism, they can also stand on their own as producing a quite distinctive problem. ${ }^{26}$ We should not be so quick to identify the traditional problem of perception with the traditional sceptical doubts. For

${ }^{26}$ See Crane (2006, 20II). 
even if we take as in general secure the knowledge afforded us through the senses, even if we do not take seriously the worry that we might be globally deluded, it remains a very significant puzzle, given at least in part considerations about nonveridical perception, just what kind of thing perception is. In particular, it remains a very significant puzzle as to just how it is that perception lays the world open to the mind.

My claim, then, has been that, regardless of his relation to scepticism, Kant certainly did think about hallucination and its relation to veridical perception. His thoughts on the matter are built into his theory of intuition. 'Intuition' is a univocal term denoting a single kind of cognitive state that is only objectdependent in the very weak sense of requiring its information-encoding matter to be given through the causal stimulation of our senses. ${ }^{27}$

\footnotetext{
${ }^{27}$ For helpful discussion and in several cases extensive comments on earlier drafts, my thanks to Lucy Allais, Ralf Bader, Craig French, Anil Gomes, Robert Hanna, Thomas Land, Erasmus Mayr, Colin McLear, Adrian Moore, Nick Tasker, Ralph Walker, Robert Watt, Kenneth R. Westphal, the audiences of the 2013 meeting of the UKKS in London and the second workshop of the CKP project in Luxembourg, and two anonymous referees.
} 


\section{References}

Allais, L. (2009) 'Kant, Non-Conceptual Content and the Representation of Space', Journal of the History of Philosophy, 47/3: 383-413.

Allais, L. (2010) 'Kant's Argument for Transcendental Idealism in the Transcendental Aesthetic', Proceedings of the Aristotelian Society, IIo: 4775 .

Allais, L. (20II) 'Idealism Enough: Response to Roche', Kantian Review, I6/3: 375-98.

Beck, L. W. (1978) 'Did the Sage of Konigsberg Have No Dreams?', in L. W. Beck Essays on Kant and Hume, 38-60. London: Yale University Press.

Brewer, B. (1999) Perception And Reason. Oxford: Oxford University Press.

Brook, A. (1997) Kant and the Mind. Cambridge: Cambridge University Press.

Buroker, J. V. (2006) Kant's Critique of Pure Reason. Cambridge: Cambridge University Press.

Cassam, Q. (1997) 'Inner Sense, Body Sense, and Kant's "Refutation of Idealism”, European Journal of Philosophy, I/2: III-27.

Crane, T. (2006) 'Is There a Perceptual Relation?', in T. S. Gendler and J. Hawthorne (eds.) Perceptual Experience, I26-46. Oxford: Oxford University Press.

Crane, T. (20II) 'The Problem of Perception', in E. N. Zalta (ed.) The Stanford Encyclopedia of Philosophy

$<$ http://plato.stanford.edu/archives/fall2or4/entries/perception-problem> accessed 25 September 2014.

Chalmers, D. J. (2004) 'The Representational Character of Experience', in B. Leiter (ed.) The Future for Philosophy, I53-8I. Oxford: Oxford University Press.

Gomes, A. (2014) 'Naïve Realism In Kantian Phrase', unpublished draft.

Grüne, S. (2009) Blinde Anschauung: Die Rolle von Begriffen in Kants Theorie sinnlicher Synthesis. Frankfurt: Klostermann.

Hanna, R. (200I) Kant and the Foundations of Analytic Philosophy. Oxford: Oxford University Press.

Hanna, R. (2005) 'Kant and Non-Conceptual Content, European Journal of Philosophy, 13/2: 247-290.

Hanna, R. (2006) Kant, Science, and Human Nature. Oxford: Oxford University Press. 
Hanna, R. (2008) 'Kantian Non-Conceptualism', Philosophical Studies, I37: 4I64.

Howell, R. (1973) 'Intuition, Synthesis, and Individuation in the Critique of Pure Reason', Nous, 7/3: 207-232.

Kant, I. (1992) Lectures on Logic, ed. M. J. Young, trans. M. J. Young. Cambridge: Cambridge University Press.

Kant, I. (1997) Critique of Pure Reason, eds. P. Guyer, A. W. Wood, trans. P. Guyer, A. W. Wood. Cambridge: Cambridge University Press.

Kant, I. (2002) Theoretical Philosophy After $178 I$, eds. H. Allison, P. Heath, trans. G. Hatfield et al. Cambridge: Cambridge University Press.

Kant, I. (2007) Anthropology, History, and Education, eds. R. B. Louden, G. Zöller, trans. M. Gregor et al. Cambridge: Cambridge University Press.

Kant, I. (2009) Lectures on Metaphysics, eds. K. Ameriks, S. Naragon, trans. K. Ameriks, S. Naragon. Cambridge: Cambridge University Press.

Kant, I. (2010) Notes and Fragments, ed. P. Guyer, trans. C. Bowman, P. Guyer, F. Rauscher. Cambridge: Cambridge University Press.

Kitcher, P. (1990) Kant's Transcendental Psychology. Oxford: Oxford University Press.

Landy, D. (2008) 'Sellars on Hume and Kant on Representing Complexes', European Journal of Philosophy, 17/2: 224-46.

Logue, H. (20II) 'The Skeptic and the Naïve Realist', Philosophical Issues, 2I/I: $268-88$.

Martin, M. G. (2004) 'The Limits of Self-Awareness', Philosophical Studies, I20: 37-89.

Martin, M. G. (2006) 'On Being Alienated', in J. Hawthorne, T. S. Gendler (eds.) Perceptual Experience, 354-410. Oxford: Clarendon Press.

McDowell, J. (1996) Mind and World. Cambridge: Harvard University Press.

McLear, C. (20II) 'Kant on Animal Consciousness', Philosophers' Imprint, II/I5: II6.

McLear, C. (20I4) 'Comments on Stefanie Grüne's "Blinde Anschauung" $<$ http://virtualcritique.wordpress.com/20I4/o8/19/colin-mclear-onstefanie-grunes-blinde-anschauung/> accessed 20 August $20 \mathrm{I} 4$.

McLear, C. (forthcoming) 'Kant on Perceptual Content', Mind.

Nudds, M. (2009) 'Recent Work in Perception: Naive Realism and its Opponents', Analysis, 69/2: 334-346. 
Roche, A. F. (20II) 'Allais on Transcendental Idealism', Kantian Review, I6/3: 35I74 .

Rosenberg, J. F. (1980) One World and our Knowledge of it. London: D. Reidel.

Rosenberg, J. F. (2005) Accessing Kant: a relaxed introduction to the "Critique of Pure Reason". Oxford: Oxford University Press.

Rukgaber, M. S. (2009) 'The Key to Transcendental Philosophy: Space, Time and the Body and Kant', Kant-Studien, Ioo: 166-86.

Russell, B. (1903) Principles of Mathematics. Cambridge: Cambridge University Press.

Sellars, W. (1968) Science and Metaphysics: Variations on Kantian Themes. London: Routledge \& Kegan Paul Ltd.

Setiya, K. (2004) 'Transcendental Idealism in the Aesthetic', Philosophy and Phenomenological Research, 68/1: 63-88.

Siegel, S. (2008) 'The Epistemic Conception of Hallucination', in A. Haddock, F. Macpherson (eds.) Disjunctivism, 205-24. Oxford: Oxford University Press.

Speaks, J. (2009) 'Transparency, intentionalism, and the nature of perceptual content', Philosophy and Phenomenological Research, 79/3: 539-73.

Stalnaker, R. C. (2008) Our Knowledge of the Internal World. Oxford: Oxford University Press.

Stehenson, A. (20II) 'Kant on Non-Veridical Experience', Kant Yearbook, 3: I-22. Stephenson, A. (20I4) 'A Deduction from Apperception?', Studi Kantiani, 27.

Sturgeon, S. (2008) 'Disjunctivism about Visual Experience', in A. Haddock, F. Macpherson (eds.) Disjunctivism, II2-43. Oxford: Oxford University Press.

Tolley, C. (2013) 'The Non-Conceptuality of the Content of Intuitions: a new approach', Kantian Review, I8/I: 107-36.

Van Cleve, J. (1999) Problems from Kant. Oxford: Oxford University Press.

Warren, D. (1998) 'Kant and the Apriority of Space', The Philosophical Review, I07: 179-224.

Westphal, K. R. (2004) Kant's Transcendental Proof of Realism. Cambridge: Cambridge University Press.

Willaschek, M. (1997) 'Der transzendentale Idealismus und die Idealität von Raum und Zeit. Eine „lückenlose” Interpretation von Kants Beweis in der ,Transzendentalen Ästhetik”, Zeitschrift für philosophische Forschung, 5I/4: $537-64$. 